\title{
Effect of stress ratio and frequency on fatigue crack growth rate of 2618 aluminium alloy silicon carbide metal matrix composite
}

\author{
NIRBHAY SINGH, RAM KHELAWAN and G N MATHUR* \\ Defence Materials \& Stores Research \& Development Establishment, GT Road, Kanpur 208 013, India
}

\begin{abstract}
Effect of stress ratio and frequency on the fatigue crack propagation of 2618 aluminium alloysilicon carbide composite were investigated at ambient temperature. With the first set of specimens, the fatigue crack growth rates were studied at three frequencies of $1 \mathrm{~Hz}, 5 \mathrm{~Hz}$ and $10 \mathrm{~Hz}$ at a stress ratio of $0 \cdot 1$ whereas the effects of stress ratios of $0 \cdot 1,0 \cdot 25$ and $0 \cdot 50$ were studied with the second set of specimens. The study showed that the fatigue crack propagation behaviour of this metal matrix composite was influenced to an appreciable extent by the stress ratio, but not by the fatigue frequencies used in this investigation.
\end{abstract}

Keywords. Aluminium alloy-SiC composite; fatigue crack; stress ratio.

\section{Introduction}

The development of new metallic materials with improved mechanical properties has been widely attempted since long. Metal matrix composites (MMCs) are one of the new materials developed recently and strengthening aluminium alloys with $\mathrm{SiC}(w / p)$ has been quite common. In order to produce such a MMC, silicon carbide fibre $(\mathrm{SiC} f)$, whisker $(\mathrm{SiC} w)$ or particulate $(\mathrm{SiCp})$ is added to commercial aluminium alloys to obtain improved mechanical properties (Divecha et al 1981; Yajima et al 1981; Arsenault 1984). Creep resistance (Nieh 1984), good thermal stability, high temperature formability and workability have been an added advantage. These composites, because of their better mechanical properties, are being used as structural materials in defence, aerospace, automotive and sports components under fatigue loading conditions.

It is believed that the stress ratio and environment have marked influence on the fatigue crack growth rate $(\mathrm{d} a / \mathrm{d} N)$ of many materials (Hartman 1965; Hartman et al 1967; Wei 1970; Coffin 1972; Imhof and Barsom 1973; Soloman and Coffin 1973; Mahoney and Paton 1974; James and Knecht 1975; Liu and McGowan 1981). However, there are controversies over the effect of loading frequency on the fatigue crack growth rate. Many investigators support the statement that frequency does not have any profound effect on crack growth rate whereas others say that it does effect $\mathrm{d} a / \mathrm{d} N$. It is generally assumed that the change of frequency has no effect on fatigue properties such as number of cycles to failure or the crack propagation rate in $\mathrm{mm} / \mathrm{cycle}$. There are, however, two situations in which fatigue properties are affected by frequency. The first is the case of fatigue enhanced by corrosion (Barsom 1971;

\footnotetext{
*Author for correspondence
}

Bamford 1977; Atkinson and Lindley 1977). The second is a frequency effect caused by strain rate sensitivity (Wulf 1974; Kawata et al 1977; Tanaka and Najima 1979).

It thus becomes of importance to examine the fatigue behaviour of these materials more closely and also to evaluate the effect of various parameters affecting the fatigue behaviour. In this paper, 2618 aluminium alloy silicon carbide metal matrix composite has been considered for the investigation of the effect of stress ratio and frequency on the fatigue crack growth rate.

\section{Specimen preparation}

2618 aluminium alloy (table 1) $+30 \%$ silicon carbide (SiC) metal matrix composite (MMC) was obtained from the Defence Metallurgical Research Laboratory, Hyderabad. The MMC was prepared through liquid casting route. The as received material was in billet form. Rectangular test specimens of size $65 \times 25 \times 5 \mathrm{~mm}$ were prepared from the bulk material in two sets. The first set of specimens consisting of five test samples was prepared for evaluating the effect of frequency on fatigue crack growth rate $(\mathrm{d} a / \mathrm{d} N)$. The second set of specimens was for evaluating the effect of stress ratio $R(R=$ minimum load/maximum load) on $\mathrm{d} a / \mathrm{d} N$ of the MMC. Single edge notched, with $\mathrm{v}$-notch of $2 \mathrm{~mm}$ length, specimens were prepared for each test.

\subsection{Fatigue tests}

To study the crack growth rate $(\mathrm{d} a / \mathrm{d} N)$ against stress intensity range $(\Delta K)$ data for each test specimen, fatigue tests in ambient atmosphere were carried out. Maximum and minimum loads for fatigue test were determined. Two sets of fatigue tests were carried out. The selected 
frequencies chosen were $10 \mathrm{~Hz}, 5 \mathrm{~Hz}$ and $1 \mathrm{~Hz}$ for investigating the effect of frequency on $\mathrm{d} a / \mathrm{d} N$. The fatigue tests were conducted at different stress ratios of $0 \cdot 1,0 \cdot 25$, and 0.50 for the second set, so as to cover most of the probable conditions experienced by this material in actual service conditions. The applied load range as well as the change in load value were recorded using the load cell of 10 tonnes hydraulic 880 model MTS Universal Testing Machine. The crack growth was measured using a travelling microscope. The fatigue tests were conducted under load control mode. From the applied loads (maximum and minimum loads), the maximum and minimum stresses were calculated. From applied stress range, $\Delta \sigma$ (calculated based on maximum and minimum loads during the crack growth determination) and the value of crack length (a) obtained from the experiment, the stress intensity factor range, $\Delta K$, was determined using the following equation

$$
\Delta K=\Delta \sigma(a)^{1 / 2} Y,
$$

where $Y=\left[1.90-0 \cdot 41(a / w)+18 \cdot 7(a / w)+18 \cdot 7(a / w)^{2}-38.48\right.$ $\left.(a / w)^{3}+53.85(a / w)^{4}\right]$ and $w$ is the width of the specimen.

The increase in crack length after various number of fatigue cycles $(N)$ at different $R$ values were recorded. Based on these recorded data and the above mentioned equation, the plots between $\mathrm{d} a / \mathrm{d} N$ vs $\Delta K$ for the given $R$ and frequencies were drawn.

\section{Results and discussion}

\subsection{Effect of frequency on fatigue crack growth rate}

The schematic diagram shows single notched fatigue test specimen having $2 \mathrm{~mm}, 45^{\circ}$ notch in it (figure 1 ). The increase in crack length $(\Delta a)$ per cycle $(N)$ was plotted on a $\log$ scale as a function of the range of stress intensity factor $(\Delta K)$ shown in figure 2 for $R=0.1$ at various frequencies of $10 \mathrm{~Hz}, 5 \mathrm{~Hz}$ and $1 \mathrm{~Hz}$. This range

Table 1. Chemical composition of 2618 aluminium alloy (in wt $\%$ ).

\begin{tabular}{ccccccc}
\hline $\mathrm{Cu}$ & $\mathrm{Si}$ & $\mathrm{Fe}$ & $\mathrm{Mg}$ & $\mathrm{Ni}$ & $\mathrm{Ti}$ & $\mathrm{Al}$ \\
1.3 & 0.25 & 1.1 & 1.5 & 1.0 & 0.07 & Balance \\
\hline
\end{tabular}
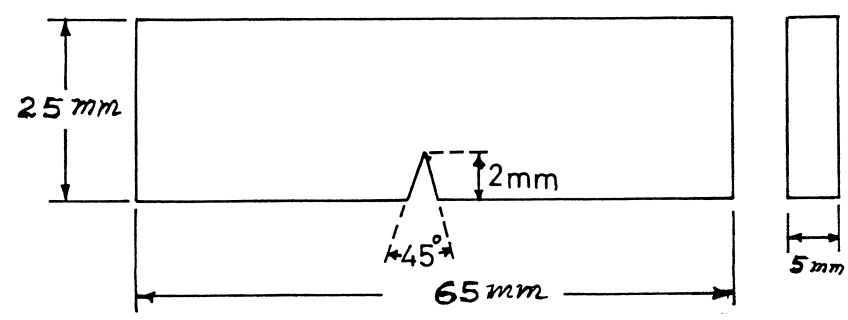

Figure 1. Single notched tensile type fatigue test specimen. of stress intensity factor is perhaps the intermediate range of stress intensity factor of the Paris law (Paris and Erdogan 1963) expressed as follows:

$$
\mathrm{d} a / \mathrm{d} N=A(\Delta K)^{n} .
$$

The results clearly show that the crack growth rate of this composite was unaffected by the frequencies in the stress intensity range of $\sim 50 \mathrm{~kg} / \mathrm{mm}^{3 / 2}$ to nearly $130 \mathrm{~kg} / \mathrm{mm}^{3 / 2}$.

The present result (figure 3) supports the statement that no appreciable effects were found in metals when tested in an inert atmosphere, inspite of the fact that some plastic deformations were noticed ahead of the crack front at $R=0 \cdot 1$ at the time of fatigue crack growth rate tests.

It is possible to characterize the extent of local plasticity at the crack tip from this frequency effect on fatigue crack growth rate. The present study showed no effect of the different frequencies like $1 \mathrm{~Hz}, 5 \mathrm{~Hz}$ and $10 \mathrm{~Hz}$ on $\mathrm{d} a / \mathrm{d} N$, it does however indicate that the plastic zone size developed at the crack tip of this material was very small.

\subsection{Effect of stress ratio $(R)$ on fatigue crack growth rate}

Generally, it has been observed that by changing the $R$ value, the $\Delta K$ also changes and as a result, based on Paris

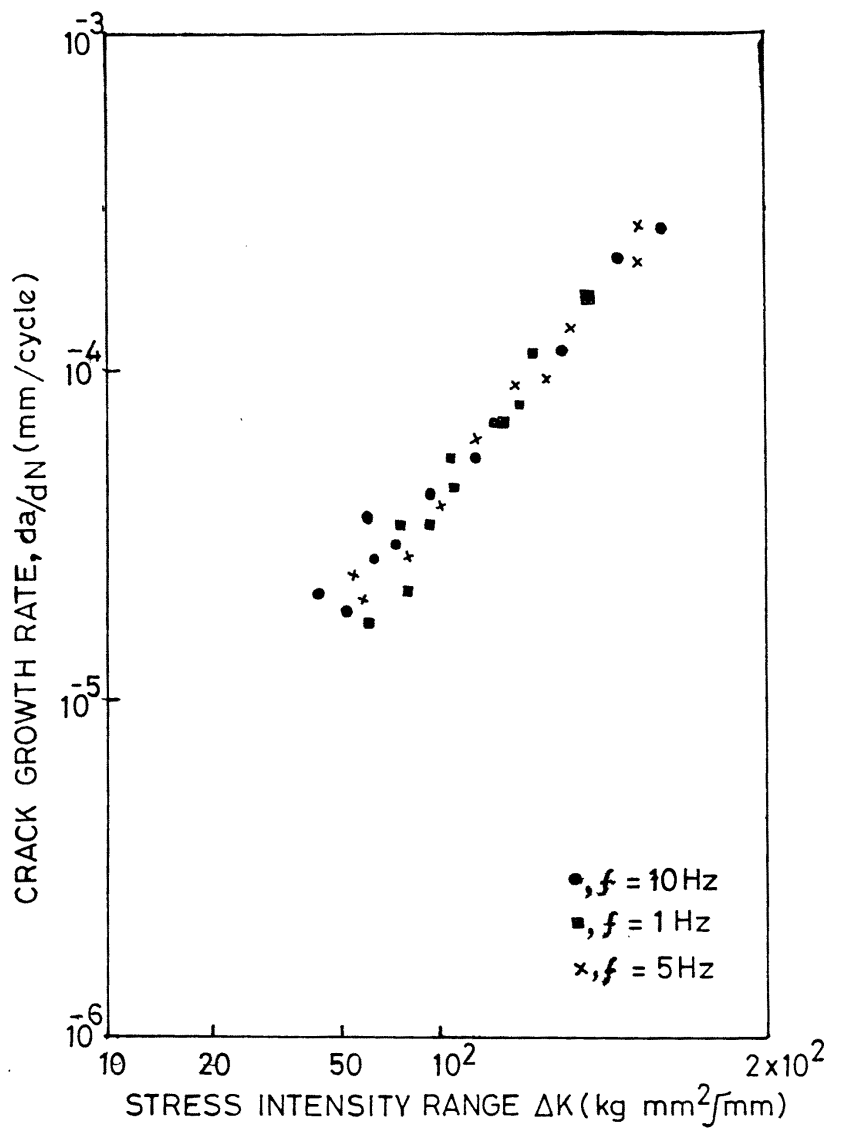

Figure 2. Crack growth rate vs $\Delta K$ for frequencies $(f)$ of $10 \mathrm{~Hz}, 5 \mathrm{~Hz}$ and $1 \mathrm{~Hz}$ at stress ratio of $0 \cdot 1$. 


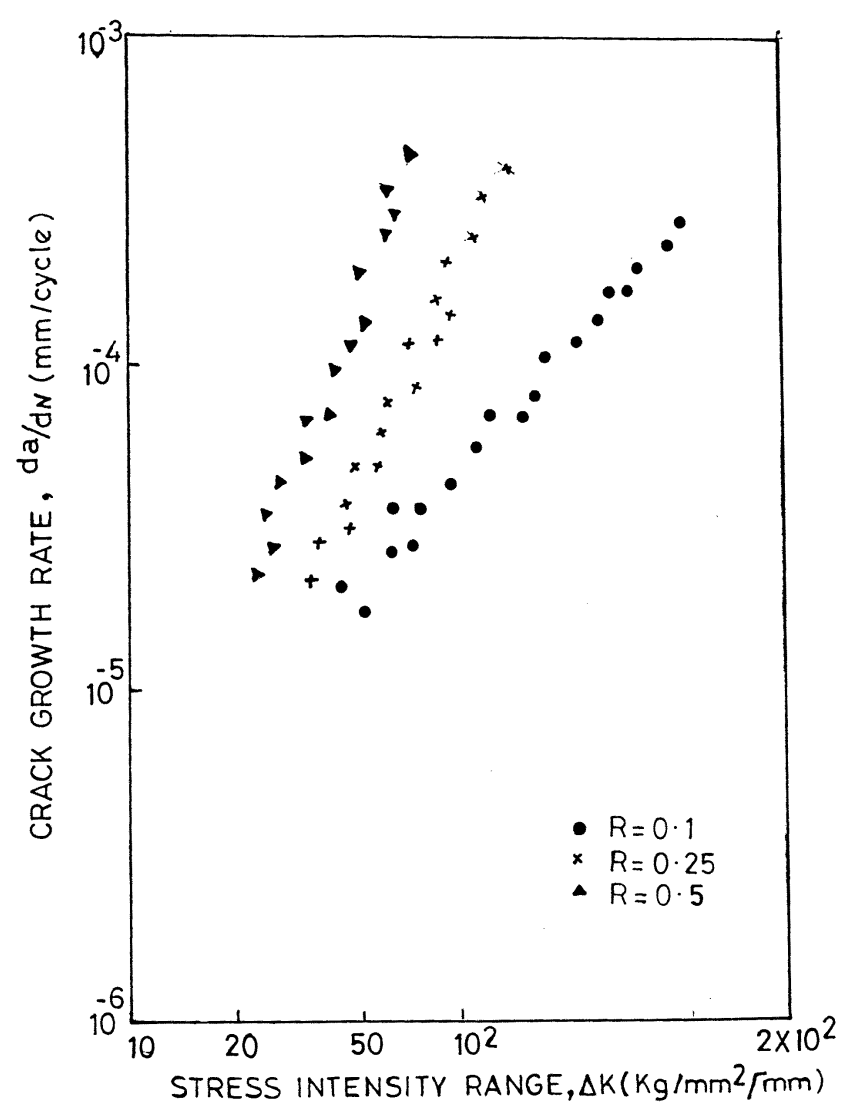

Figure 3. Crack growth rate vs $\Delta K$ for stress ratios of $R=0 \cdot 1$, 0.25 and 0.5 at frequency $10 \mathrm{~Hz}$.

equation, the crack growth rate should also change. Accordingly, if $R$ is increased, the crack growth rate should also increase. But, Paris law does not account for crack growth characteristics at both low and high levels of $\Delta K$. The crack growth rates at high $\Delta K$ values increases with increasing $R$ and little sensitivity has been observed at lower $\Delta K$ levels. At high $\Delta K$ values, the crack growth rates follow the relationship as indicated by Forman et al (1967)

$$
\mathrm{d} a / \mathrm{d} N=C \Delta K^{n} /\left[(1-R) K_{\mathrm{c}}-\Delta K\right],
$$

where, $c$ is crack length, $K_{\mathrm{c}}$ is critical stress intensity factor.

It can be seen that the simple power relationship (2) has been modified by a factor of $1 /\left[(1-R)_{\mathrm{c}}-\Delta K\right]$, which highlights that $\mathrm{d} a / \mathrm{d} N$ decreases with decreasing stress ratio, $R$, and decreasing fracture toughness, $K_{\mathrm{c}}$, both of which lead to a higher crack growth rates at a given $\Delta K$ level.

In the present investigation the crack growth rate of the composite was affected appreciably by changing the $R$ value. Higher crack growth rates could be clearly noticed by increasing the $R$ value. This material follows the relationship (3) put forward by Forman et al (1967) so far as the effect of stress ratio on the fatigue crack growth rate of this aluminium alloy composite was concerned.

\section{Conclusions}

The following conclusions were arrived at from this investigation:

(I) The crack growth rate of 2618 aluminium $+30 \% \mathrm{SiC}$ MMC was not affected by the frequency inspite of the fact that little plastic deformation was noticed at the crack tip of the composite when it was initially loaded to a maximum load.

(II) Fatigue crack propagation at intermediate crack growth rates followed a power law of the form $\mathrm{d} a / \mathrm{d} N=A$ $\Delta K^{n}$ with value of $m$ depending on stress ratio.

(III) Increasing the stress ratio increased the crack growth rates of the composite.

\section{Acknowledgements}

The authors are sincerely grateful to Late Dr M C Pandey, Scientist, Defence Metallurgical Research Laboratory, Hyderabad, for providing the composite.

\section{References}

Arsenault R J 1984 Mater. Sci. Engg. 64171

Atkinson J D and Lindley T C 1977 Conference on the influence of environment on fatigue (London: Inst. Mech. Engg.) p. 65

Bamford W H 1977 Conference on the influence of environment on fatigue (London: Inst. Mech. Engg.) p. 51

Barsom J M 1971 Proc. int. conf. on corrosion fatiguechemistry, mechanics and microstructure (Storrs, Connecticut: NASE) p. 424

Coffin L F Jr 1972 Met. Trans. 31777

Divecha A P, Fishman S G and Karmakar S D 1981 J. Metal 33 12

Forman R G, Kearney V E and Engle R M 1967 J. Basic Eng. Trans. ASME 89459

Hartman A 1965 Int. J. Frac. Mech. 1167

Hartman A, Jacobs F J, Nederveen A and deRijk P 1967 NLRTN/M 2182

Imhof E J and Barsom J M 1973 ASTM STP 536182

James L A and Knecht R L 1975 Met. Trans. A6 109

Kawata K, Hashimoto S and Kurokawa K 1977 IUTAM symposium (Tokyo: University of Tokyo Press)

Liu H W and McGowan J J 1981 AFWAL-TR 814036

Mahoney M H and Paton N E 1974 Nucl. Tech. 23290

Nieh T G 1984 Metall. Trans. A15 139

Paris P and Erdogan F J 1963 J. Basic Eng. Trans. ASME 85528

Solomon H D and Coffin L F 1973 ASTM STP 520112

Tanaka K and Nojima T 1979 Mechanical properties at high rates of strain (Oxford: The Inst. of Physics) p. 166

Yajima S, Okamura K, Matsuzawa T, Tanaka J and Hayase T 1981 Proc. Japan-US conference, Tokyo, Japan (Oxford: Pergamon) p. 232

Wei R P 1970 Engg. Frac. Mech. 1633

Wulf T 1974 Mechanical properties at high rates of strain (Oxford: The Inst. of Physics) p. 48 